Article

\title{
Compassion and Job Performance: Dual-Paths through Positive Work-Related Identity, Collective Self Esteem, and Positive Psychological Capital
}

\author{
Sung-Hoon Ko ${ }^{1}$ and Yongjun Choi ${ }^{2, *}$ \\ 1 Graduate School of Education, Kyonggi University, Suwon 16227, Korea; baumhoffnung@kyonggi.ac.kr \\ 2 College of Business Administration, Hongik University, Seoul 04066, Korea \\ * Correspondence: yongjun.choi@hongik.ac.kr; Tel.: +82-2-320-1735
}

Received: 4 November 2019; Accepted: 26 November 2019; Published: 28 November 2019

\begin{abstract}
The purpose of this study is to examine the unexplored mechanisms through which employee job performance is affected by compassion experienced at work. While the relationship between compassion and job performance is relatively well established in the literature, our knowledge of the actual mechanisms underlying this relationship is still in a nascent state. In this study, we propose two paths through which increased job performance results from workplace compassion. Our empirical results, obtained through 360 full-time employees including 182 males and 178 females working in South Korea, provide support for the serial double mediation effects of positive work-related identity and collective self-esteem in the positive relationship between compassion experienced at work and job performance. In addition, the positive relationship between workplace compassion and job performance is mediated by positive psychological capital.
\end{abstract}

Keywords: compassion; positive work-related identity; collective self-esteem; positive psychological capital; job performance

\section{Introduction}

It is inevitable for employees to experience suffering at work. Organizations are affective environments where employees experience job-related demands and situations that trigger distress on a constant basis; for example, negative affective reactions can arise from job dissatisfaction [1]. Negative work events (e.g., conflict) and acute job demands, in particular, harm employee wellbeing by triggering negative emotions and even job burnout [2-6]. In addition, employees often have the painful experience of disconnection or detachment from their organizations and from other organizational members [7]. Such phenomena are detrimental to both organizational and employee performance, factors that are critical to organizational profit, effectiveness, and ultimately sustainability [8,9]. Positive organizational psychologists suggest that, for employees experiencing suffering at work, the expressing of concern and caring by coworkers is integral [10]. Positive organizational psychologists have coined it as compassion: "an interpersonal process involving the noticing, feeling, sense-making, and acting that alleviates the suffering of another person" [11]. Despite the importance of workplace compassion in creating sustainable working environments, however, less is known about why or through what mechanisms compassion works in organizational settings [12]. Specifically, scholars have paid scant attention to how and why compassion brings about positive effects, such as improved job performance, at work. Therefore, in this study, we aim at investigating the mechanisms through which workplace compassion can increase employee job performance.

Past studies have shown that workplace compassion helps employees acquire positive work attitudes and behaviors. For instance, employees experiencing compassion are likely to experience 
positive emotions at work, which in turn increases their organizational commitment [10]. Furthermore, previous studies have shown that employees experiencing compassion are more likely to show higher job performance [13-15]. Regarding the relationship between compassion and job performance, only a few studies have attempted to explore the underlying mechanisms. For example, Chu (2014) showed that, using the example of a nurse, positive moods mediate the relationship between compassion and job performance [14]. Moon et al. (2016) also demonstrated that, from a sample of service employees, experiencing compassion at work leads to higher job performance by increasing employee creativity and by reinforcing positive work-related identity [16]. However, most studies were conducted by using unique samples, such as nurses [14] or service employees [16]. Hence, to further confirm and generalize previous findings, additional study is needed. In addition, more empirical study is necessary to examine the underexplored mechanisms thorough which compassion increases job performance.

This study seeks to advance our knowledge of the mechanisms underlying workplace compassion and improved job performance. First, by extending Moon et al. (2016), we test for the dual mediation effects of positive work-related identity and collective self-esteem in the relationship between compassion and job performance [16]. By doing so, we aim to provide a much clearer picture of how workplace compassion helps employees achieve higher job performance. Second, drawing upon the literature on positive psychological capital, we suggest positive psychological capital as a mediator explaining the relationship between compassion and job performance. By doing so, we seek to advance the literature by examining and testing this unique perspective. Lastly, we aim at increasing the generalizability of past findings concerning the relationship between compassion and job performance by using a larger sample of full-time employees across variety of industries. In sum, by exploring the dual paths through which compassion increases an employee's job performance and by sampling across diverse industries, this study aims at providing organizations seeking sustainable workplaces with practical policy implications, and at advancing our knowledge about the effects of compassion at work.

\section{Hypotheses Development}

\subsection{Compassion and Positive Work-Related Identity}

We proposed that workplace compassion could serve as a driver of positive work-related identity. Social identity theory $[17,18]$ suggests that individuals shape their identities by interacting with others. In the work context, mainly drawing upon social identity theory, Dutton et al. (2010) emphasize the importance of positive work-related identity [19]. They suggest four theoretical typologies of positive work-related identity-virtue, evaluative, developmental, and structural perspective. First, the virtue perspective suggests that employees construct positive work-related identity "when it is imbued with virtuous attributes" (p. 269). Second, the evaluative perspective suggests that employees shape their positive work-related identities "when individuals regard the identity more favorable" (p. 269). Third, the development perspective, which can be either progressive or adaptive, suggests employee perceptions of its contents moving in the direction of higher stages of development or fitting with internal or external standards. Finally, the structural perspective, which can be either balanced or complementary, suggests interactions between personal and social identities enhance one's positive work-related identity.

From the virtue perspective, employees who experience compassion at work are likely to perceive virtue at work [19], which, in turn, increases their positive work-related identity. Furthermore, from an evaluative perspective, workplace compassion allows employees to perceive themselves being favorably treated by others because their coworkers express concern and even are willing to help them alleviate the pain they experience in the workplace. Third, from a developmental perspective, they are likely to feel the sense of self-growth while experiencing compassionate acts by others at work. Lastly, from a structural perspective, they are likely to perceive an adequate fit between their self-identities and social identities (i.e., feeling part of a group or having organizational membership) because they 
are likely to be socially included by experiencing such compassionate acts by others. In sum, we predicted that employees who experience compassion at work are more likely to construct a positive work-related identity.

Hypothesis H1. Compassion experienced in the workplace is positively related to positive work-related identity.

\subsection{Positive Work-Related Identity and Collective Self-Esteem}

We suggest that employees who construct positive work-related identity are more likely to perceive high collective self-esteem. Specifically, according to social identity theory $[17,18]$, as a result of positive comparisons between their own groups and others, employees are likely to feel proud of being part of their social groups through the experiences of positive emotions at work. In addition, they are likely to experience positive interactions with other organizational members [20], resulting in high collective self-esteem. Past studies demonstrated that positive work-related identity increases an employee's affective commitment $[10,16,19,21]$. These positive and affective reactions enable employees to shape their social identities as a part of the workgroup they belong to. In other words, they are very likely to favorably evaluate their social groups (i.e., workgroups or organizations), which, in turn, allow them to perceive high collective self-esteem. Hence, we hypothesized the following:

Hypothesis H2. Positive work-related identity is positively related to collective self-esteem.

\subsection{Collective Self-Esteem and Job Performance}

In general, the positive relationship between self-esteem and performance is well established in the literature. For example, in educational settings, students who report high self-esteem are more likely to perceive academic success [22,23]. In organizational settings as well, past studies suggest that employees who report high self-esteem are more likely to show better performance $[24,25]$.

Self-consistency theory $[26,27]$ suggests that "individuals will engage in and find satisfying those behavioral roles which maximize their sense of cognitive balance or consistency" [27]. Employees who are high in collective self-esteem have a high level of belief regarding the quality of their teams [28]. Hence, positive work-related identity can promote employees to feel proud of being a part of their social groups and further facilitate their behaviors of spreading positive information about their organizations to others. Furthermore, according to the self-consistency theory, in order to achieve and maintain their positive perceptions about the social groups they are being part of, high collective self-esteem employees will exert more effort toward their job performance. Past studies on organization-based self-esteem also provide support for our prediction. While emphasizing the importance of self-esteem in organizations, Pierce et al. (1989) suggest a construct called organization-based self-esteem, which refers to "the degree to which an individual believes him/herself to be capable, significant, and worthy as an organizational member" [29]. A meta-analysis provides support that organization-based self-esteem has a positive relationship with job performance because organization-based self-esteem facilitates employees' work behaviors increasing their job performance [30]. Thus, we hypothesized the following:

Hypothesis H3. Collective self-esteem is positively related to job performance.

\subsection{Serial Multiple Mediation of Positive Work-Related Identity and Collective Self-Esteem}

Previous arguments led us to explore the serial multiple mediation effects of positive work-related identity and job performance in the relationship between compassion and job performance. From the lens of social identity theory $[17,18]$, employees who experience compassionate acts by other 
organizational members are likely to favorably evaluate their work environments through intergroup social comparisons. This, in turn, enables employees to construct a strong positive work-related identity, strengthening their collective self-esteem. It is more than likely that high collective self-esteem employees equate their success with the success of their social groups. Hence, they would increase the level of their work effort to help increase the success of their social groups. Hence, we hypothesized the following:

Hypothesis H4. The relationship between compassion experienced in the workplace and job performance is sequentially mediated by positive work-related identity and collective self-esteem.

\subsection{Mediation of Positive Psychological Capital}

In addition to the serial-mediation effects of positive work-related identity and collective self-esteem in the relationship between compassion and job performance, we suggest that positive psychological capital could explain another path of how experienced compassion increases an employee's job performance. The definition of psychological capital is as follows:

"An individual's positive psychological state of development characterized by: (1) having confidence (efficacy) to take on and put in the necessary effort to succeed at challenging tasks; (2) making a positive attribution (optimism) about succeeding now and in the future; (3) persevering toward goals and, when necessary, redirecting paths to goals (hope) in order to succeed; and (4) when beset by problems and adversity, sustaining and bouncing back and even beyond (resilience) to attain success" [31].

That is, employees with high psychological capital are filled with positive psychological resources allowing them to be efficacious, optimistic, hopeful, and resilient. The positive relationship between positive psychological capital and job performance is well established in the literature (e.g., [15,32,33]). For example, Gooty et al. [32] showed that employees with high positive psychological capital show better in-role performance because they are filled with positive psychological resources helping them to stay committed to their goals within an organization. Avey, Reichard, Luthans, and Mhatre's [33] meta-analysis also provides support for the positive relationship between positive psychological capital and job performance.

In this study, we proposed that compassion experienced at work plays an important role in helping employees shape positive psychological capital. In other words, we suggested that compassion experienced at work could help employees build positive psychological resources so that they can better handle obstacles to accomplishing their goals. Since it is inevitable for employees to avoid challenging work events depleting their psychological resources [1,34-36], employees need adequate sources that can replenish their psychological resources. The job demands-resources (JD-R) model suggests that social support is an important situational factor that buffers an employee's drainage in psychological resources, which is integral for keeping them engaged at work, which, in turn, helps them achieve their work goals $[34,37,38]$. Employees who experience compassion at work are likely to perceive that their coworkers provide them with social support because coworkers care about and actively respond to their pain at work with warmth and kindness [16,39]. That is, coworkers who express care and warmth for others act as contextual resources to those who experience suffering at work. All in all, it is likely the social support mechanism initiated by the compassionate acts of coworkers can replenish one's psychological resources (i.e., positive psychological capital), which in turn increases one's job performance. Therefore, we hypothesized the following:

Hypothesis H5. The relationship between compassion experienced in the workplace and job performance is mediated by positive psychological capital. 


\section{Method}

\subsection{Study Participants and Procedure}

Full-time employees from large-sized South Korean companies were recruited to voluntarily participate in an anonymous survey. Specifically, based on mission, vision, and values that can be found on company websites, one member of our research team contacted the HR representatives of several companies emphasizing positive and compassionate organizational cultures. Among the companies he contacted, eight companies decided to voluntarily participate in this study. Upon their approval, he visited the eight companies and gave a short presentation encouraging voluntary employee participation. As a result, 360 employees completed online surveys. The majority of the participants were in their thirties $(N=132 ; 36.7 \%)$ and held bachelor's degrees $(N=283 ; 78.6 \%)$. Among the participants, $182(50.6 \%)$ were male. Many of the participants worked for their current organization ranging from 1 to 5 years $(N=199 ; 55.3 \%)$ followed by those between 5 and 10 years $(N=116 ; 32.2 \%)$.

\subsection{Measures}

Following Brislin's (1980) translation and back translation procedure [40], all of the items originally written in English were translated into Korean. Except for compassion, all the survey items were measured using a five point Likert scale $(1=$ strongly disagree to $5=$ strongly agree $)$.

\subsubsection{Compassion}

Compassion was measured using three items from Lilius et al. [10]. Lilius et al. [10] defined compassion as "noticing another person's suffering, empathically feeling that person's pain, and acting in a manner that intended to ease the suffering" (pp. 194-195), which fits the purpose of our study. Past studies on compassion, such as Moon et al. [16] and Hur et al. [41], also used the same measurement providing empirical evidence of acceptable reliability and validity of the scale. Following Lilius et al. [10], we measured the frequency of experienced compassion on the three aspects of work-(a) on the job, (b) from the supervisor, and (c) from coworkers, ranging from $1=$ never to $5=$ almost all the time. The reliability coefficient for compassion was 0.78 .

\subsubsection{Positive Work-Related Identity}

Positive work-related identity was measured using four items from Bednar et al. [42] grounded on the discussion by Dutton et al. [19]. While discussing the little consensus about what constitutes to the positive work-related identity in the literature, Dutton et al. [18] defined positive work-related identity by four perspectives (i.e., virtue, evaluative, developmental, and structural). Thus, we concluded Bednar et al. [42] could capture the comprehensive picture of positive work-related identity. Although empirical studies on positive work-related identity are still limited, past studies, such as Moon et al. [16] and Hur et al. [41], also used the same measurement providing adequate evidence of its reliability and validity. Sample items read "As a member of this organization, I am a person of virtuous character" and "As a member of this organization, I exemplify virtuous qualities". The reliability coefficient for positive work-related identity was 0.91 .

\subsubsection{Collective Self-Esteem}

We used an 8-item measure of collective self-esteem from Crocker and Luhtanen [27], which defines collective self-esteem as the extent to which an individual value the importance and values of his/her group and proudly spread positive information about his/her organizations to others. Thus, we concluded that the measurement fits the purpose of exploring our research questions. Sample items include "I feel good about working for our organization" and "In general, I'm glad to be an employee in this company". The coefficient alpha reliability for the scale was 0.77 . 


\subsubsection{Job Performance}

Job performance was measured using 10 items from Williams and Anderson [43]. Williams and Anderson [43] suggests the two dimensions of employee performance (i.e., in-role and extra-role performance). Of the two dimensions of employee performance, similar to the past studies on job performance focusing on task-related performance, such as Hsu et al. [44], we used the 10 items for in-role performance to measure job performance. Sample items read "I adequately complete assigned duties" and "I meet formal performance requirements of the job." The reliability coefficient for job performance was 0.87 .

\subsubsection{Positive Psychological Capital}

We used a 24-item measure of positive psychological capital from Youssef and Luthans [45]. Youssef and Luthans [45] define psychological capital as the extent to which an individual experiences hope, optimism, self-efficacy, and resilience for the future of one's belonging organization. Past studies on psychological capital, such as Çetin [46], Avey et al. [47], and Peterson et al. [48], also used the same measurement providing adequate evidence of its reliability and validity. Sample items include "I feel confident analyzing a long-term problem to find a solution" and "If I should find myself in a jam, I could think of many ways to get out of it". The coefficient alpha reliability for the scale was 0.89 .

\section{Results}

\subsection{Data Analysis}

We calculated Cronbach's alphas for internal consistencies. Cronbach alphas for our study variables were satisfactorily ranging from 0.77 to 0.91 [49]. Furthermore, a confirmatory factor analysis (CFA) was conducted to evaluate the discriminant as well as convergent validity of the study variables. We found satisfactory results from the CFA $\left(\chi^{2}(902)=1603.6111 ; p<0.001 ; \mathrm{CFI}=0.908\right.$; TLI $=0.901$; RMSEA $=0.047$ ). Item and factor loadings in our measurement models all exceeded 0.67. Averaged variance extracted (AVE) also all exceeded 0.6 providing the satisfactory evidence of discriminant validity [50]. We also tested variance inflation factor (VIF) to detect potential multicollinearity issues in regression results. VIFs ranged from 1.153 to 1.287 . Hence, we concluded that our study did not have serious multicollinearity issues.

Table 1 shows means, standard deviations, zero-order correlations, and the squared root of AVEs in our study variables. As we expected, compassion was positively related to positive work-related identity $(r=0.21, p<0.01)$ and positive psychological capital $(r=0.37, p<0.01)$. In addition, collective self-esteem $(r=0.47, p<0.01)$ and positive psychological capital $(r=0.52, p<0.01)$ were positively related to job performance.

Table 1. Descriptive statistics.

\begin{tabular}{cccccccc}
\hline & Mean & S.D. & $\mathbf{1}$ & $\mathbf{2}$ & $\mathbf{3}$ & $\mathbf{4}$ & $\mathbf{5}$ \\
\hline 1. Compassion & 3.71 & 0.65 & 0.82 & & & & \\
2. Positive work-related identity & 3.57 & 0.69 & $0.21^{* *}$ & 0.84 & & & \\
3. Collective self-esteem & 3.59 & 0.54 & $0.30^{* *}$ & $0.47^{* *}$ & 0.84 & & \\
4. Job performance & 3.79 & 0.62 & $0.29^{* *}$ & $0.50^{* *}$ & $0.47^{* *}$ & 0.83 & \\
5. Positive psychological capital & 3.52 & 0.44 & $0.37^{* *}$ & $0.51^{* *}$ & $0.58^{* *}$ & $0.52^{* *}$ & 0.86 \\
\hline
\end{tabular}

Note: $N=360 ;{ }^{* *} p<0.01$; the numbers along the diagonal are the square root of the AVE (averaged variance extracted).

\subsection{Common Method Variance}

Since all the study variables were collected from a single source using a cross-sectional research design, we could not completely rule out the possibility that our research design might bias our study results. Thus, following Podaskoff et al. [51], Harman's single-factor test was conducted. To do this, we conducted an un-rotated exploratory factor analysis (EFA). As a result of EFA, five factors were 
derived, and all the five factors exceeded eigenvalues of 1 with the highest variance explained of $22 \%$. Since the factor with the highest variance explained was less than $50 \%$ of the total variance explained, we concluded that our results did not suffer from serious common method bias [51,52].

\subsection{Hypotheses Testing}

To test our hypotheses, we utilized path analysis. As shown in Table 2, compassion was positively related to positive work-related identity $(b=0.48, S E=0.31, C R=6.65, p<0.001)$, providing support for Hypothesis H1. The relationship between positive work-related identity and collective self-esteem was also positive and statically significant $(b=0.62, S E=0.07, C R=9.40, p<0.001)$. Thus, Hypothesis H2 was supported. As predicted, collective self-esteem was also positively associated with job performance $(b=0.98, S E=0.14, C R=7.23, p<0.001)$ lending support for Hypothesis H3.

Table 2. Path analysis results.

\begin{tabular}{cccccc}
\hline Hypothesis & Path & b & SE & CR & $p$ \\
\hline H1 & Compassion $\rightarrow$ PWRI & 0.48 & 0.31 & 6.65 & $<0.001$ \\
H2 & PWRI $\rightarrow$ CSE & 0.62 & 0.07 & 9.40 & $<0.001$ \\
H3 & CSE $\rightarrow$ JP & 0.68 & 0.14 & 7.23 & $<0.001$ \\
\hline
\end{tabular}

Note: $N$ = 360; PWRI = positive work-related identity; CSE = collective self-esteem; JP = job performance.

To test our serial mediation hypothesis, we utilized a bootstrapping method using PROCESS [53,54] Table 3 shows the indirect effects, 95\% bootstrapped confidence intervals (CIs), and total indirect effect. As shown in Table 3, compassion was positively related to job performance via positive work-related identity (indirect effect $=0.07, S E=0.03, C I=[0.07,0.22]$ ) as well as collective self-esteem (indirect effect $=0.05, S E=0.02, C I=[0.02,0.08])$. More importantly, the bootstrapping results showed that positive work-related identity and collective self-esteem sequentially mediate the positive relationship between compassion and job performance (indirect effect $=0.02, S E=0.01, C I=[0.01,0.04]$ ). Hence, Hypothesis $\mathrm{H} 4$ was supported.

Table 3. Indirect effects for the double-mediation effects (positive work-related identity and collective self-esteem).

\begin{tabular}{ccccc}
\hline \multirow{2}{*}{ From $\rightarrow$ to } & \multicolumn{4}{c}{ Indirect Effects } \\
\cline { 2 - 5 } & Estimate & CI $_{\text {low }}$ & CI $_{\text {high }}$ & BootSE \\
\hline Total indirect effect & 0.13 & 0.07 & 0.22 & 0.04 \\
Compassion $\rightarrow$ PWRI $\rightarrow$ JP & 0.07 & 0.03 & 0.13 & 0.03 \\
Compassion $\rightarrow$ CSE $\rightarrow$ JP & 0.05 & 0.02 & 0.08 & 0.02 \\
Compassion $\rightarrow$ PWRI $\rightarrow$ CSE $\rightarrow$ JP & 0.02 & 0.01 & 0.04 & 0.01 \\
\hline
\end{tabular}

Note. $N=360$; bootstrap confidence intervals (CIs) were constructed using 5000 resamples; PWRI = positive work-related identity; CSE = collective self-esteem; JP = job performance.

Table 4 shows the mediation testing results for Hypothesis H5. Bootstrapping results using PROCESS indicate that compassion was positively related to job performance via compassion (indirect effect $=0.04, \mathrm{SE}=0.04, \mathrm{CI}=[0.10,0.28])$. Thus, Hypothesis H5 was supported. 
Table 4. Mediating effect of positive psychological capital.

\begin{tabular}{cccc}
\hline \multicolumn{4}{c}{ Direct Effect of Compassion on Job Performance } \\
\hline Effect & SE & $t$-value & $p$-value \\
\hline 0.80 & 0.05 & 1.70 & 0.09 \\
\hline \multicolumn{4}{c}{ Indirect effect of compassion on job performance (via compassion) } \\
\hline Effect & Boot SE & BootLLCI & BootULCI \\
\hline 0.17 & 0.04 & 0.10 & 0.28 \\
\hline Note. $N=360 ;$ bootstrap confidence intervals $(C I s)$ were constructed using 5000 resamples.
\end{tabular}

\section{Discussion and Conclusions}

We examined the dual paths through which workplace compassion leads to the enhancement of employee job performance. Our results demonstrated that positive work-related identity and collective self-esteem serially mediated the positive relationship between workplace compassion and job performance. In addition, we found that positive psychological capital played a mediating role in the relationship. In sum, our results provided empirical evidence demonstrating the importance of social support mechanisms in explaining how and why compassion leads to positive employee behaviors.

\subsection{Discussion}

Since the late 1990s, scholars have paid attention to the roles of compassion at work. Specifically, positive organizational psychologists took the lead by conducting qualitative studies investigating the role of compassion in an organizational setting. The seminal work by Lilius et al. [10] facilitated the rise of empirical studies on workplace compassion. Our study was one of the few empirical studies on compassion at work demonstrating the unique mechanisms through how experienced compassion at work could energize employee job performance.

For the first path of our model, while positive organizational psychologists have mainly focused on the relationships between compassion and positive emotions, our study aimed at exploring the roles of positive work-related identity and collective self-esteem in unwrapping the underlying mechanism of how compassion leads to high job performance. Specifically, consistent with our hypotheses grounded on the social identity theory $[17,18]$ and self-consistency theory $[26,27]$, our results showed that employees who experienced compassion at work helped them construct positive work-related identity, leading to high collective self-esteem as a result of positive interactions with other organizational members, which, in turn, energized their job performance. That is, as we predicted, it turns out that positive work-related identity and collective self-esteem serially mediated the positive relationship between compassion at work and job performance. For the second path in our model, as we hypothesized, our results showed that positive psychological capital mediated the positive relationship between compassion at work and job performance because, analogous to the JD-R model [34,37,38], experiencing compassion served as a social support replenishing one's psychological resources (i.e., psychological capital), which helped them reach their full potential to successfully complete their jobs. All in all, our results provided empirical evidence of unique dual-paths of how compassion at work could facilitate employee job performance.

\subsection{Implications}

The findings from this study extended our knowledge of compassion at work in the following ways. First, our findings provided a much deeper understanding of why and through what mechanisms workplace compassion increases job performance. Specifically, drawing upon social consistency theory $[26,27]$ as well as social identity theory $[17,18]$, we extended Moon et al. [16] by demonstrating the serial mediation effects of positive work-related identity and collective self-esteem. Hence, our 
study advanced workplace compassion literature by introducing and examining a new mediator, collective self-esteem, in the link between compassion and job performance.

Second, our study advanced our knowledge by theorizing and empirically testing the social support mechanism in the compassion-job performance link. Specifically, drawing on the JD-R model, our results demonstrated that compassion that was experienced could help employees build up psychological resources (i.e., positive psychological capital), which in turn enhances employee job performance. To our knowledge, this was the first empirical study that explored positive psychological capital as a mediating variable for explaining the effects of compassion at work. Therefore, our study advanced the theory of compassion at work by exploring positive psychological capital as a novel mechanism in understanding the compassion-job performance link.

Third, our findings offered more generalizable findings about the mechanisms explaining the positive effects of compassion at work. Past studies examining the mechanisms through which compassion leads to job performance mainly relied on specific contexts, such as nursing [14] or service industries [16]. To avoid potential organizational or industry effects on the hypothesized relationship and to ensure that our findings would be generalizable, we collected data across various organizations and industries. Hence, our findings added new empirical insights to the literature by showing that the positive effects of compassion at work were applicable across various organizations and industries.

Our findings offer practical insights for practitioners by suggesting that organizations could help employees enhance their job performance by providing them with compassionate experiences in the workplace. By nature, employees face and experience either negative or challenging events at work, which drain their psychological resources. It can be especially true in industries where emotional demands are relatively high. However, it is also true that psychological resource drainage as such exists in virtually any job [55]. Moreover, given the importance of employee psychological wellbeing in the sustainable workplace [56,57], it seems integral for organizations to facilitate employees' compassionate experiences at work so that they can replenish their psychological resources. To do so, organizations can develop a compassionate climate by expressing or providing or emphasizing genuine care, assistance, and forgiveness for every organizational member.

\subsection{Limitations and Future Research Directions}

Despite its contributions, our study was not without limitations, and we believed future research to address these could further advance our knowledge of the effects of compassion at work. First, although our study benefitted from survey sample characteristics, we acknowledged that our findings were limited in that we sampled from a single country, South Korea. Given that moral values such as compassion can vary across cultures [58], future reproduction of our findings using samples from different cultural contexts could be beneficial.

Second, our study focused on the effects of compassion on job performance. Rotundo and Sackett [59] however, suggest that employees engage in several types of workplace behaviors, and these are closely related to their performance, such as task, citizenship, and counterproductive performance. Contextual performance, such as citizenship behaviors, is critical for a sustainable workplace [35]. Moreover, despite the possibility that compassion (or lack thereof) can either reduce or increase an employee's counterproductive behavior, past studies have mostly focused on the positive outcomes of compassion at work. Therefore, future research could benefit from examining the effects of compassion on contextual performance, such as citizenship behaviors and counterproductive behaviors, which can further extend our findings.

Third, we collected data relying on self-ratings using a cross-sectional research design. Thus, although our Harman's one-factor test results allowed us to be less concerned about common method bias, we acknowledged that we could not rule out the possibility that self-rated variables might inflate our findings. Particularly with job performance, research shows that self-rated performance tends to be more lenient than other types of rating [60]. In addition, due to the nature of cross-sectional research design, we could not completely rule out the possibility that our research design may bias the 
results due to its preclusion of causal inference inferences [61,62]. Hence, for more rigorous findings, constructive replication of our study using a longitudinal research design along with multiple source data will be helpful.

Fourth, because all the scales we used were not available in Korean, we followed Brislin's [39] suggestion to translate the original survey items in on language (i.e., English) into another one (i.e., Korean). Although Brislin's [39] method is widely used in social sciences (e.g., [35,63]), we acknowledged that the development of scales for our study variables, such as compassion and positive work-related identity, specifically designed to the Korean context could be more beneficial. Thus, future research may constructively replicate our theory through the development and usage of new measurements in Korean context.

Fifth, we acknowledged the possibility that other factors, such as gender, might affect the effects of compassion at work. For example, in our study, about half of our study participants were male. Our $t$-tests revealed that, whereas there were no significant differences in compassion and job performance, positive work-related identity and psychological capital showed significant differences across the two genders. Hence, future research could benefit by examining the roles of genders in investigating the mechanisms through how compassion leads to positive outcomes, such as job performance and extra-role behaviors. Furthermore, given the limited studies on compassion using Asian samples, future research could conduct cross-cultural studies on workplace compassion.

Author Contributions: S.-H.K. wrote the first draft of this manuscript, designed the model, and conducted and analyzed the empirical test results. Y.C. supplemented several parts of the paper, including theories and discussion, and refined the entire article. All authors contributed to writing this manuscript.

Funding: This research received no external funding.

Conflicts of Interest: The authors declare no conflict of interest.

\section{References}

1. Weiss, H.M.; Cropanzano, R. Affective events theory: A theoretical discussion of the structure, causes and consequences of affective experiences at work. In Research in Organization Behavior; Staw, B.M., Cummings, L.L., Eds.; JAI Press: Greenwich, CT, USA, 1996; pp. 1-74.

2. Crawford, E.R.; LePine, J.A.; Rich, B.L. Linking job demands and resources to employee engagement and burnout: A theoretical extension and meta-analytic test. J. Appl. Psychol. 2010, 95, 834-848. [CrossRef] [PubMed]

3. Friedman, R.A.; Tidd, S.T.; Currall, S.C.; Tsai, J.C. What goes around comes around: The impact of personal conflict style on work conflict and stress. Int. J. Confl. Manag. 2000, 11, 32-55. [CrossRef]

4. Jawahar, I.M.; Stone, T.H.; Kisamore, J.L. Role conflict and burnout: The direct and moderating effects of political skill and perceived organizational support on burnout dimensions. Int. J. Stress Manag. 2007, 14, 142-159. [CrossRef]

5. Lee, R.T.; Ashforth, B.E. A meta-analytic examination of the correlates of the three dimensions of job burnout. J. Appl. Psychol. 1996, 81, 123-133. [CrossRef] [PubMed]

6. Nahrgang, J.D.; Morgeson, F.P.; Hofmann, D.A. Safety at work: A meta-analytic investigation of the link between job demands, job resources, burnout, engagement, and safety outcomes. J. Appl. Psychol. 2011, 96, 71-94. [CrossRef] [PubMed]

7. McCann, L. Disconnected amid the networks and chains: Employee detachment from company and union after offshoring. Br. J. Ind. Relat. 2013, 52, 237-260. [CrossRef]

8. Johnson, J.W. Toward a better understanding of the relationship between personality and individual job performance. In Personality and Work; Barrick, M., Ryan, A.M., Eds.; Jossey-Bass: San Francisco, CA, USA, 2003; pp. 83-120.

9. Motowildo, S.J.; Borman, W.C.; Schmit, M.J. A theory of individual differences in task and contextual performance. Hum. Perform. 1997, 10, 71-83. [CrossRef]

10. Lilius, J.M.; Worline, M.C.; Maitlis, S.; Kanov, J.; Dutton, J.E.; Frost, P. The contours and consequences of compassion at work. J. Organ. Behav. 2008, 29, 193-218. [CrossRef] 
11. Dutton, J.E.; Workman, K.M.; Hardin, A.E. Compassion at work. Ann. Rev. Organ. Psychol. 2014, 1, $277-304$. [CrossRef]

12. Frost, P.J.; Dutton, J.E.; Maitlis, S.; Lilius, J.M.; Kanov, J.M.; Worline, M.C. Seeing organizations differently: Three lenses on compassion. In The SAGE Handbook of Organization Studies; Sage: London, UK, 2006; pp. 843-866. [CrossRef]

13. Aboul-Ela, G.M.B.E. Reflections on workplace compassion and job performance. J. Hum. Values 2017, 23, 234-243. [CrossRef]

14. Chu, L.-C. Mediating positive moods: The impact of experiencing compassion at work. J. Nurs. Manag. 2014, 24, 59-69. [CrossRef] [PubMed]

15. Luthans, F.; Avolio, B.J.; Walumbwa, F.O.; Li, W. The psychological capital of Chinese workers: Exploring the relationship with performance. Manag. Organ. Rev. 2005, 1, 249-271. [CrossRef]

16. Moon, T.-W.; Hur, W.-M.; Ko, S.-H.; Kim, J.-W.; Yoo, D.-K. Positive work-related identity as a mediator of the relationship between compassion at work and employee outcomes. Hum. Factor. Ergon. Man. 2016, 26, 84-94. [CrossRef]

17. Tajfel, H. Social identity and intergroup behavior. Soc. Sci. Inform. 1974, 13, 65-93. [CrossRef]

18. Tajfel, H. The exit of social mobility and the voice of social change. Soc. Sci. Inform. 1975, 14, 101-118. [CrossRef]

19. Dutton, J.E.; Roberts, L.M.; Bednar, J. Pathways for positive identity construction at work: Four types of positive identity and the building of social resources. Acad. Manag. Rev. 2010, 35, 265-293. [CrossRef]

20. Rego, A.; Ribeiro, N.; Cunha, M.P.e.; Jesuino, J.C. How happiness mediates the organizational virtuousness and affective commitment relationship. J. Bus. Res. 2011, 64, 524-532. [CrossRef]

21. Allen, T.D. Family-supportive work environments: The role of organizational perceptions. J. Vocat. Behav. 2001, 58, 414-435. [CrossRef]

22. Lane, J.; Lane, A.M.; Kyprianou, A. Self-efficacy, self-esteem and their impact on academic performance. Soc. Behav. Personal. 2004, 32, 247-256. [CrossRef]

23. Bankston, C.L.; Zhou, M. Being well vs. doing well: Self-esteem and school performance among immigrant and nonimmigrant racial and ethnic groups. Int. Migr. Rev. 2006, 36, 389-415. [CrossRef]

24. Ferris, D.L.; Lian, H.; Brown, D.J.; Pang, F.X.J.; Keeping, L.M. Self-esteem and job performance: The moderating role of self-esteem contingencies. Pers. Psychol. 2010, 63, 561-593. [CrossRef]

25. Pierce, J.L.; Gardner, D.G. Self-esteem within the work and organizational context: A review of the organization-based self-esteem literature. J. Manag. 2004, 30, 591-622. [CrossRef]

26. Korman, A.K. Toward a hypothesis of work behavior. J. Appl. Psychol. 1970, 54, 31-41. [CrossRef]

27. Korman, A.K. Hypothesis of work behavior revisited and an extension. Acad. Manag. Rev. 1976, 1, 50-63. [CrossRef]

28. Crocker, J.; Luhtanen, R. Collective self-esteem and ingroup bias. J. Pers. Soc. Psychol. 1990, 58, 60-67. [CrossRef]

29. Pierce, J.L.; Gardner, D.G.; Cummings, L.L.; Dunham, R.B. Organization-based self-esteem: Construct definition, measurement, and validation. Acad. Manag. J. 1989, 32, 622-648. [CrossRef]

30. Bowling, N.A.; Eschleman, K.J.; Wang, Q.; Kirkendall, C.; Alarcon, G. A meta-analysis of the predictors and consequences of organization-based self-esteem. J. Occup. Organ. Psychol. 2010, 83, 601-626. [CrossRef]

31. Luthans, F.; Avolio, B.J.; Avey, J.B.; Norman, S.M. Positive psychological capital: Measurement and relationship with performance and satisfaction. Pers. Psychol. 2007, 60, 541-572. [CrossRef]

32. Gooty, J.; Gavin, M.; Johnson, P.D.; Frazier, M.L.; Snow, D.B. In the eyes of the beholder: Transformational leadership, positive psychological capital, and performance. J. Leadersh. Org. Stud. 2009, 15, 353-367. [CrossRef]

33. Avey, J.B.; Reichard, R.J.; Luthans, F.; Mhatre, K.H. Meta-analysis of the impact of positive psychological capital on employee attitudes, behaviors, and performance. Hum. Resour. Dev. Q. 2011, 22, 127-152. [CrossRef]

34. Bakker, A.B.; Demerouti, E. The job demands-resources model: State of the art. J. Manag. Psychol. 2007, 22, 309-328. [CrossRef]

35. Fredrickson, B.L. The role of positive emotions in positive psychology: The broaden-and-build theory of positive emotions. Am. Psychol. 2001, 56, 218-226. [CrossRef] [PubMed] 
36. Ko, S.-H.; Choi, Y.; Rhee, S.-Y.; Moon, T.W. Social capital and organizational citizenship behavior: Double-mediation of emotional regulation and job engagement. Sustainability 2018, 10, 3600. [CrossRef]

37. Bakker, A.B.; Demerouti, E.; de Boer, E.; Schaufeli, W.B. Job demands and job resources as predictors of absence duration and frequency. J. Vocat. Behav. 2003, 62, 341-356. [CrossRef]

38. Bakker, A.B.; Demerouti, E.; Verbeke, W. Using the job demands-resources model to predict burnout and performance. Hum. Resour. Manag. 2004, 43, 83-104. [CrossRef]

39. Dutton, J.E.; Worline, M.C.; Frost, P.J.; Lilius, J. Explaining compassion organizing. Admin. Sci. Quart. 2006, 51, 59-96. [CrossRef]

40. Brislin, R.W. Translation and content analysis of oral and written material. In Handbook of Cross-Cultural Psychology; Triandis, H.C., Berry, J.W., Eds.; Allyn \& Bacon: Boston, MA, USA, 1980; pp. 389-444.

41. Hur, W.-M.; Moon, T.-W.; Rhee, S.Y. Exploring the relationships between compassion at work, the evaluative perspective of positive work-related identity, service employee creativity, and job performance. J. Serv. Mark. 2016, 30, 103-114. [CrossRef]

42. Bednar, J.; Owens, B.; Dutton, J.; Roberts, L.M. Finding the Positive in Individual's Identities: An Investigation of the Reliability and Validity of a Six Different Measures of Positive Organizational Identity; Working Paper; Stephen, M., Ed.; Ross School of Business, University of Michigan: Ann Arbor, MI, USA, 2011.

43. Williams, L.J.; Anderson, S.E. Job satisfaction and organizational commitment as predictors of organizational citizenship and in-role behaviors. J. Manag. 1991, 17, 601-617. [CrossRef]

44. Hsu, Y.P.; Chun-Yang, P.; Pi-Hui, T.; Ching-Wei, T. Managerial coaching, job performance, and team commitment: The mediating effect of psychological capital. Adv. Manag. Appl. Econ. 2019, 9, 101-125. [CrossRef]

45. Youssef, C.M.; Luthans, F. Positive organizational behavior in the workplace. J. Manag. 2007, 33, 774-800. [CrossRef]

46. Çetin, F. The effects of the organizational psychological capital on the attitudes of commitment and satisfaction: A public sample in Turkey. Eur. J. Soc. Sci. 2011, 21, 373-380.

47. Avey, J.B.; Wernsing, T.S.; Luthans, F. Can positive employees help positive organizational change? Impact of psychological capital and emotions on relevant attitudes and behaviors. J. Appl. Behav. Sci. 2008, 44, 48-70. [CrossRef]

48. Peterson, S.J.; Luthans, F.; Avolio, B.J.; Walumbwa, F.O.; Zhang, Z. Psychological capital and employee performance: A latent growth modeling approach. Pers. Psychol. 2011, 64, 427-450. [CrossRef]

49. Nunnally, J.C. Psychometric Theory, 2nd ed.; McGraw-Hill: New York, NY, USA, 1978.

50. Fornell, C.; Larcker, D.F. Evaluating structural equation models with unobservable variables and measurement error. J. Mark. Res. 1981, 18, 39-50. [CrossRef]

51. Podsakoff, P.M.; MacKenzie, S.B.; Lee, J.-Y.; Podsakoff, N.P. Common method biases in behavioral research: A critical review of the literature and recommended remedies. J. Appl. Psychol. 2003, 88, 879-903. [CrossRef] [PubMed]

52. Podsakoff, P.M.; Organ, D.W. Self-reports in organizational research: Problems and prospects. J. Manag. 1986, 12, 531-544. [CrossRef]

53. Shrout, P.E.; Bolger, N. Mediation in experimental and nonexperimental studies: New procedures and recommendations. Psychol. Methods 2002, 7, 422-445. [CrossRef]

54. Preacher, K.J.; Hayes, A.F. Asymptotic and resampling strategies for assessing and comparing indirect effects in multiple mediator models. Behav. Res. Methods 2008, 40, 879-891. [CrossRef]

55. Miner, A.; Glomb, T.; Hulin, C. Experience sampling mood and its correlates at work. J. Occup. Organ. Psychol. 2005, 78, 171-193. [CrossRef]

56. Ha, S. Surface acting and job-related affective wellbeing: Preventing resource loss spiral and resource loss cycle for sustainable workplaces. Sustainability 2018, 10, 1099. [CrossRef]

57. Kong, H.; Jeon, J.-E. Daily emotional labor, negative affect state, and emotional exhaustion: Cross-level moderators of affective commitment. Sustainability 2018, 10, 1967. [CrossRef]

58. Wines, W.A.; Napier, N.K. Toward an understanding of cross-cultural ethics: A tentative model. J. Bus. Ethics. 1992, 11, 831-841. [CrossRef]

59. Rotundo, M.; Sackett, P.R. The relative importance of task, citizenship, and counterproductive performance to global ratings of job performance: A policy-capturing approach. J. Appl. Psychol. 2002, 87, 66-80. [CrossRef] [PubMed] 
60. Heidemeier, H.; Moser, K. Self-other agreement in job performance ratings: A meta-analytic test of a process model. J. Appl. Psychol. 2009, 94, 353-370. [CrossRef]

61. Lindell, M.K.; Whitney, D.J. Accounting for common method variance in cross-sectional research designs. J. Appl. Psychol. 2001, 86, 114-121. [CrossRef]

62. Maxwell, S.E.; Cole, D.A. Bias in cross-sectional analyses of longitudinal mediation. Psychol. Methods 2007, 12, 23-44. [CrossRef]

63. Goo, W.; Choi, W.; Choi, Y. Coworkers' organizational citizenship behaviors and employees' work attitudes: The moderating roles of perceptions of organizational politics and task interdependence. J. Manag. Organ. 2019, 1-25. [CrossRef] 